\title{
A New Synthesis of the Sex Pheromone of the Indian Meal Moth Plodia Interpunctella Hb. (Lepidoptera, Pyralidae)
}

\author{
ADRIANA-MARIA ANDREICA*, LUCIA GANSCA, IRINA CIOTLAUS, IOAN OPREAN \\ Babes-Bolyai University-Raluca Ripan Institute for Research in Chemistry, Natural Product Laboratory, 30 Fantanele Str., 400294, \\ Cluj-Napoca, Romania
}

\begin{abstract}
New synthesis of (9Z,12E)-9,12-tetradecadien-1-yl acetate, the sex pheromone of the indian meal moth Plodia interpunctella (Lepidoptera, Pyralidae), were developed. The synthesis was based on a $C_{8}+C_{2}=C_{10}$ and $C_{10}+C_{4}=C_{12}$ coupling scheme. 1,8-Octanediol is the starting material used in the synthesis. The route involves, as the key step, the use of the mercury derivative of the terminal alkyne $\omega$-functionalised as intermediate. The first coupling reaction took place between 1-tert-butoxy-8-bromo-octane and lithium acetylide-ethylendiamine complex obtaining 1-tert-butoxy-dec-9-yne, which is transformed in di[tert-butoxy-dec-9-yne]mercury. In the second coupling reaction, the mercury derivative was directly lithiated and then alkylated with (E)-1-bromo-2-butene obtaining 1-tert-butoxy-(9-yne,12E)-9,12-tetradecaenyne. After stereoselective reduction in the presence of $\mathrm{Ni}-\mathrm{P}_{2}$ catalyst and acetylation gave (9Z,12E)-9,12-tetradecadien-1-yl acetate with $82 \%$ isomeric purity.
\end{abstract}

Keywords: (9Z,12E)-9,12-tetradecadien-1-yl acetate, Lepidoptera, sex pheromone, Plodia interpunctella

Plodia interpunctella $\mathrm{Hb}$. (Lepidoptera, Pyralidae) is a cosmopolitan pest, spread in Mediterranean and temperate climates, has spread a lot in the warehouses in the country, where it attacks wheat, corn, sorghum, millet, rice, soybean, sunflower germ, largely affecting germination faculty. Also, it attacks flours, dried fruits and vegetables, herbs, pastries and more. In our country, adults can be seen consistently from late May until early October. They are active at twilight and remain in the vicinity of products, even in warehouses.

The synthesis of $(9 \mathrm{Z}, 12 \mathrm{E})-9,12$-tetradecadiene-1-yl acetate is well known in the literature [2-10]. The pheromone has been prepared by the Wittig reaction [11], Grignard reagent reaction with allyl bromide in the presence of copper (I) salts [12], Wittig condensation between triphenyl-phosphonium (E)-3-pentenylide and 9-acetoxy-1-nonanal using either potassium in HMPT [13], cross-coupling reaction [14], coupling 2-(8-chloro-1-octyloxy)tetrahydropyran with lithium acetylide followed by reaction of lithium salt with (E)-1-bromo-2-butene [15]. A similar route was used by Su et al., beginning with 1,9-decadiyne and crotyl alcohol [16].

The aim of our work was to investigate a new synthesis of $(9 \mathrm{Z}, 12 \mathrm{E})-9,12$-tetradecadien-1-yl acetate, using the mercury derivative of the terminal alkyne $\omega$-functionalized as intermediate, because Plodia interpunctella is a world-wide economically important pest of stored products and processed food.

\section{Experimental part}

Materials and characterization methods

All the materials used were of reagent grade and were purchased from Sigma-Aldrich and Merck.

GC-MS analysis were performed on a GC-MS spectrometer Agilent 7890A GC\&5975 GC/MS Serie MSD.

${ }^{1} \mathrm{H}-\mathrm{NMR}(300 \mathrm{MHz})$ and ${ }^{13} \mathrm{C}-\mathrm{NMR}(75 \mathrm{MHz})$ spectra were recorded at $\mathrm{rt}$ in $\mathrm{CDCl}_{3}$ on a Brüker $300 \mathrm{MHz}$ spectrometer, using TMS line as reference.

A Perkin Elmer Spectrometer Model 700 was used for IR spectra.

\section{8-Bromo-1-octanol (3)}

To a solution $73 \mathrm{~g}$ (0.500 moles) of 1,8-octanediol (2) solved in $300 \mathrm{~mL}$ benzene was added $86.17 \mathrm{~mL}$ hydrobromic acid $47 \%$. The reaction mixture was refluxed for $2.5 \mathrm{~h}$. The organic layer was separated and washed with brine, saturated $\mathrm{NaHCO}_{3}$ solution and dried over anhydrous $\mathrm{MgSO}_{4}$. After removal of the solvent the product was purified by liquid-liquid distribution (petroleum ether:aqueous methanol), $62.7 \mathrm{~g}$ of 8-bromo-1-octanol (3) was obtained. $\mathrm{n}_{\mathrm{D}}{ }^{18}=1.478$, Yield $=60 \%$, GC purity: $97 \%$.

Mass spectrum (m/z, \%): 190(<1), 178(<1), 164(<1), 151(<1), 111(<1), 109(<1), 148(34.80), 97(26.47), 83(43.13), 69(87.25), 55(100), 41(74.01), 31(29.41).

*email: adriana.andreica@gmail.com 


\section{1-tert-Butoxy-8-bromo-octan (4)}

To a solution $65 \mathrm{~g}$ (311 mmoles) of 8-bromo-1-octanol (3) and $344.5 \mathrm{~mL}$ tert-butyl-methyl-ether was added dropwise $20.5 \mathrm{~mL}$ concentrated sulfuric acid under cooling. The reaction mixture was maintained at $40^{\circ} \mathrm{C}$. The reaction was checked by TLC on silica gel $\mathrm{G}$ (benzene : ether $=2: 1$, detection with $\mathrm{H}_{2} \mathrm{SO}_{4} \mathrm{~d}=1.25$ ). The reaction mixture was diluted with water. After removal of the tertbutyl-methyl-ether under reduced pressure, the mixture was extracted with ethyl ether $(3 \times 50 \mathrm{~mL})$. The combined ethereal extracts were washed with saturated $\mathrm{NaHCO}_{3}$ solution up to basic and dried over anhydrous $\mathrm{Na}_{2} \mathrm{SO}_{4}$. After the removal of the solvent, $53.56 \mathrm{~g}$ of 1-tert-butoxy-8-bromo-octan (4) were obtained. b.p. $=102^{0}-104^{0} \mathrm{C} / 3 \mathrm{mmHg}, \mathrm{n}_{\mathrm{D}}{ }^{18}=1.456$, Yield $=90 \%$, GC purity: $97 \%$.

Mass spectrum (m/z, \%): 277(<1), 236(<1), 219(<1), 177(<1), 163(<1), 137(<1), 121(<1), 97(<1), 83.29(<1), 59(100), 41(21.56).

\section{1-tert-Butoxy-dec-9-yne (6)}

All operations were performed in an inert gas atmosphere and under stirring.

To a stirred and cooled $\left(0^{\circ} \mathrm{C}\right)$ suspension of $3.8 \mathrm{~g}(41.30$ mmoles) lithium acetylide-ethylendiamine complex (5) in $20.65 \mathrm{~mL}$ anhydrous dimethyl sulfoxide was added $5.47 \mathrm{~g}$ (20.64 mmoles) of 1-tert-butoxy-8-bromo-octan (4). The reaction mixture was stirred at room temperature for $6 \mathrm{~h}$. It was poured into ice water and extracted with hexane. The combined hexane extracts were washed with water, brine and dried over anhydrous $\mathrm{MgSO}_{4}$. After removal of the solvent, $4.04 \mathrm{~g}$ of 1-tert-butoxy-dec-9-yne (6) were obtained. b.p. $=94^{0}-100^{\circ} \mathrm{C} / 4 \mathrm{mmHg}, \mathrm{n}_{\mathrm{D}}{ }^{18}=1.441$, Yield $=84.52 \%$, GC purity: $90.62 \%$.

Mass spectrum (m/z, \%): 195(24.50), 177(<1), 154(<1), 153(<1), 135(<1), 121(<1), 107(<1), 95(28.43), 81(35.78), 67(6.37), 59(100), 57(89.21), 55(26.96), 41(46.07), 29(17.64).

\section{Di[1-tert-butoxy-dec-9-yne]mercury (7)}

To $6.53 \mathrm{~g}$ of potassium iodide dissolved in $6.53 \mathrm{~mL}$ water was added $2.64 \mathrm{~g}$ mercury (II) chloride and the mixture was stirred till the mercury salt was dissolved. To the mixture were added $5 \mathrm{~mL}$ of $10 \%$ sodium hydroxide solution. After external cooling of reaction mixture with ice, were added dropwise $1.89 \mathrm{~g}$ (9 mmoles) of 1-tert-butoxy-dec-9-yne (6) dissolved in $28 \mathrm{~mL}$ cooling ethyl alcohol. The reaction mixture was perfected 1 hour under stirring. The obtained precipitate was filtrated and washed on the filter with cooling aqueous ethylic alcohol 50\%. After drying were obtained $3.15 \mathrm{~g}$ of di(1-tert-butoxy-dec-9-yne) mercury (7). Yield: 57\%, m.p. = $102^{\circ} \mathrm{C}$

\section{1-tert-Butoxy-(9-yne,12E)-9,12-tetradecaenyne (9)}

All operations were performed in an inert gas atmosphere and under stirring.

$7 \mathrm{~g}$ (11.3 mmoles) of di[1-tert-butoxy-dec-9-yne]mercury (7) in $29 \mathrm{~mL}$ diglyme was treated with $0.15 \mathrm{~g}$ lithium (25.42 mmoles) at $100^{0}-115^{\circ} \mathrm{C}$ for 1 hour. $3.5 \mathrm{~g}\left(25.92\right.$ mmoles) of (E)-1-bromo-2-butene (8) dissolved in $7 \mathrm{~mL}$ diglyme was added dropwise at $78^{0}-80^{\circ} \mathrm{C}$ then the temperature was raised to $85^{\circ}-86^{\circ} \mathrm{C}$ under stirring for 5 hours. The mixture was poured out over $100 \mathrm{~g}$ of break ice. The reaction mixture was extracted with petroleum ether. The ethereal solution was washed successively with $10 \% \mathrm{HCl}$, water and brine till neutral $\mathrm{pH}$ of the washings. After drying over anhydrous $\mathrm{MgSO}_{4}$, the solvent was removed and $4 \mathrm{~g}$ of 1-tert-butoxy-(9-yne,12E)9,12-tetradecaenyne (9) was obtained. Yield: $71 \%$, GC purity: $80 \%$.

Mass spectrum (m/z, \%): 249(<1), 235(<1), 208(<1), 207(<1), 179(<1), 161(<1), 150(8.74), 135(13.59), 121(9.7), 107(15.53), 94(42.72), 79(45.63), 57(100), 41(47.57), 29(19.42).

\section{1-tert-Butoxy-(9Z,12E)-9,12-tetradecadiene (10)}

1-tert-Butoxy-(9-yne,12E)-9,12-tetradecaenyne (9) was hydrogeneted at 1-tert-butoxy-(9Z,12E)-9,12-tetradecadiene (10) in the presence of the $\mathrm{Ni}-\mathrm{P}_{2} / \mathrm{EDA}$ catalyst, prepared in situ according to the standard procedure [20]. 1-tert-Butoxy-(9Z,12E)-9,12tetradecadiene (10) was obtained in yield of $78 \%$, GC purity: $82 \%$.

Mass spectrum (m/z, \%): 266(<1), 251(<1), 210(<1), 192(<1), 166(<1), 149(<1), 135(<1), 121(<1), 109(13.72), 95(33.3), 81(42.16), 67(40.2), 57(100), 41(51.96), 29(19.61).

${ }^{1} \mathrm{H}-\mathrm{RMN}\left(\mathrm{CDCl}_{3}, 300 \mathrm{MHz}\right): 1.13$ (9H, s, 3CH3), 1.23 (10H, s, 5CH2), 1.43-1.50 (2H, m, CH2), 1.58-1.60 (3H, m, CH3), $1.93-$ $2.00(2 \mathrm{H}, \mathrm{m}, \mathrm{CH} 2), 2.64-2.68(2 \mathrm{H}, \mathrm{m}, \mathrm{CH} 2), 3.27(2 \mathrm{H}, \mathrm{t}, \mathrm{J}=6 \mathrm{~Hz}, \mathrm{OCH} 2), 5.29-5.40(4 \mathrm{H}, \mathrm{m}, 2 \mathrm{HC}=\mathrm{CH})$.

${ }^{13} \mathrm{C}-\mathrm{RMN}\left(\mathrm{CDCl}_{3}, 75 \mathrm{~Hz}\right): 18.0(\mathrm{CH} 3), 26.3(\mathrm{CH} 2), 27.1(\mathrm{CH} 2), 27.6(\mathrm{CH} 2), 29.3(\mathrm{CH} 2), 29.5(\mathrm{CH} 2), 29.6(\mathrm{CH} 2), 29.7(\mathrm{CH} 2)$, $30.5(\mathrm{CH} 2), 30.7(\mathrm{CH} 2), 61.7(\mathrm{OCH} 2), 72.5$ (tertiary carbon), $125.1(\mathrm{CH}=), 127.6(\mathrm{CH}=), 129.7(\mathrm{CH}=), 130.5(\mathrm{CH}=)$.

\section{(9Z,12E)-9,12-tetradecadien-1-yl acetate (1)}

All operations were performed in an inert gas atmosphere and under stirring.

At $2.5 \mathrm{~g}$ (9.3 mmoles) of 1-tert-butoxy-(9Z,12E)-9,12-tetradecadiene (10) was added $3 \mathrm{~mL}$ of acetic anhydride and $1 \mathrm{~mL}$ $\mathrm{BF}_{3} / \mathrm{AcOH}$ complex. The reaction mixture was kept at room temperature. The reaction development was checked up by TLC on silica gel $\mathrm{G}$ (benzene : ether $=10: 2$, detection with $\mathrm{H}_{2} \mathrm{SO}_{4} \mathrm{~d}=1.25$ ). The solution was poured on crushed ice, extracted with petroleum ether, washed with aqueous $\mathrm{NaHCO}_{3}$ and brine. After drying over anhydrous $\mathrm{MgSO}_{4}$ and removal of the solvent was obtained $1.6 \mathrm{~g}$ of (9Z,12E)-9,12-tetradecadien-1-yl acetate (1). Yield: 70\%, GC purity: $82 \%$.

Mass spectrum (m/z, \%): 252(<1), 209(<1), 192(9.46), 177(<1), 163(<1), 149(6.76), 135(10.81), 121(18.92), 110(13.51), 95(41.89), 79(70.27), 67(81.08), 55(52.7), 43(100), 29(13.51). 


\section{Results and discussions}

For the synthesis of $(9 \mathrm{Z}, 12 \mathrm{E})-9,12$-tetradecadiene-1-yl acetate (1) we explored the pathway outlined in scheme 1 . The synthesis were based on $\mathrm{C}_{8}+\mathrm{C}_{2}=\mathrm{C}_{10}$ and $\mathrm{C}_{10}+\mathrm{C}_{4}=\mathrm{C}_{14}$ coupling schemes, starting from 1,8-octane-diol, the route involving the use of the mercury derivative of the terminal alkyne $\omega$-functionalised as intermediate.

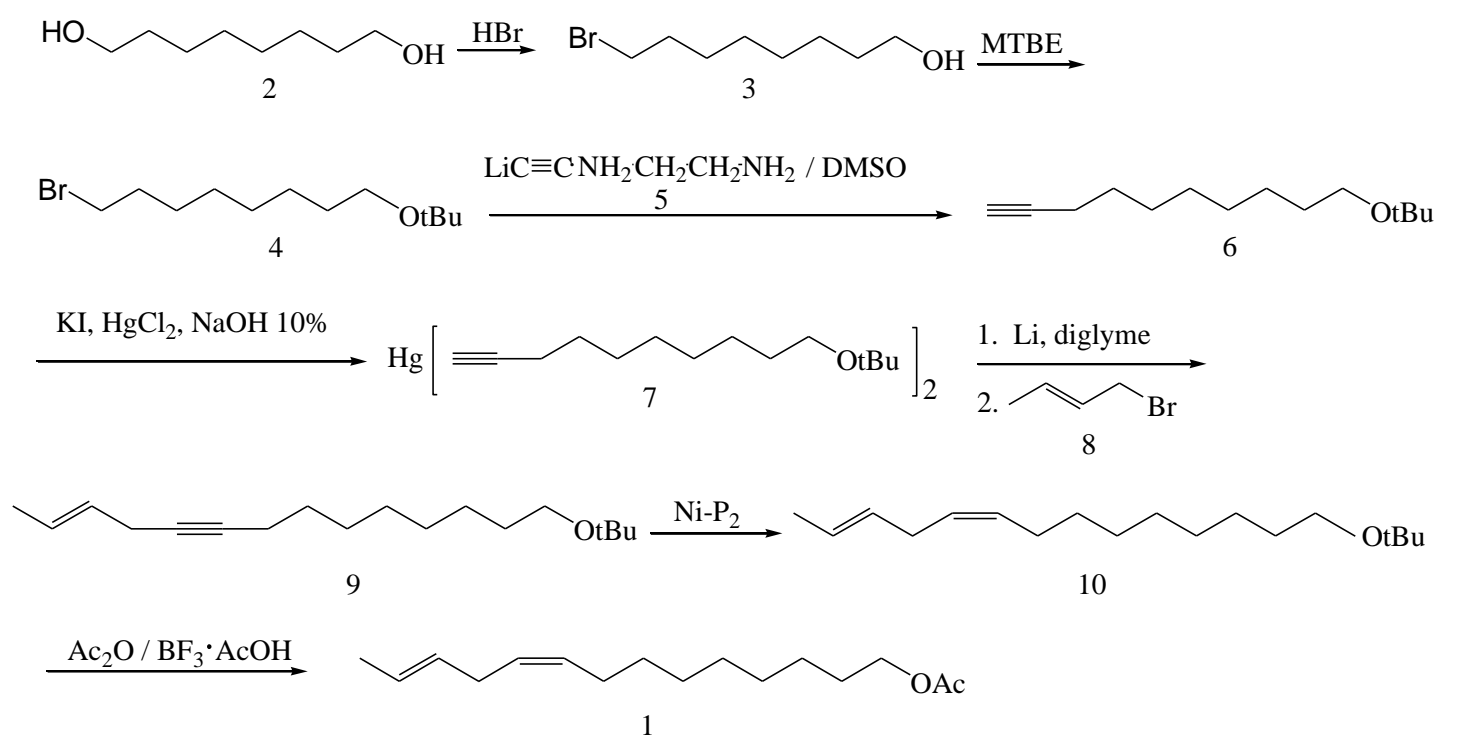

Scheme 1

Use has been made of methyl-t-butyl-ether [17] in acid catalysis in order to protect the -OH function of the 8-bromo-1-octanol (3). The first coupling reaction [18] was performed by adding 1-tert-butoxy-8-bromo-octan (4) to lithium acetylide-ethylendiamine complex in dimethyl sulfoxide. 1-tert-Butoxy-dec-9-yne (6) was checked by means of IR spectrum (film, cm -1: $895 \mathrm{~m}, 1110 \mathrm{vs,}$ 1220 vs, $2160 \mathrm{w}-\mathrm{C} \equiv \mathrm{C}-, 3280 \mathrm{~s} \equiv \mathrm{CH}$ ), which presents the vibration of terminal triple bond.

1-tert-Butoxy-dec-9-yne (6) with mercuric chloride in an aqueous solution containing potassium iodide and sodium hydroxide (Nessler`s reagent) [19] was precipitated as di[1-tert-butoxy-dec-9-yne]mercury (7).

The key step in our acetilenic route consisted in transmetallation of compound 7, which was directly lithiated by treating with metal lithium in diglyme and then alkylated with (E)-1-bromo-2-butene (8), obtaining 1-tert-butoxy-(9-yne,12E)-9,12-tetradecaenyne (9).

The molecular peak of 1-tert-butoxy-(9-yne,12E)-9,12-tetradecaenyne (9) was not identified, the mass spectrum presenting only characteristic fragmentations shown in figure 1: the base peak in the spectrum $(\mathrm{m} / \mathrm{z}=59)$, the peak $\mathrm{m} / \mathrm{z}=57$ generated by the very stable carbocation $+\mathrm{C}\left(\mathrm{CH}_{3}\right)_{3}$, the peaks of medium intensity at $\mathrm{m} / \mathrm{z}=79$ and $\mathrm{m} / \mathrm{z}=55$ corresponds to vinylic cleavages, the peaks of medium intensity at $\mathrm{m} / \mathrm{z}=94$ and $\mathrm{m} / \mathrm{z}=41$ corresponds to propargylic cleavages.

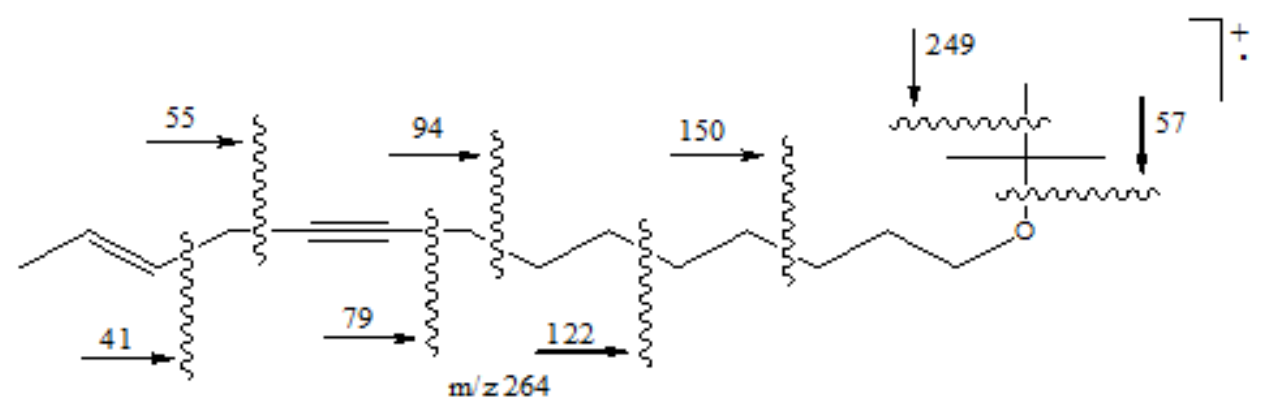

Figure 1

Compound 9 was hydrogenated using Ni-P/EDA catalyst [20], obtaining 1-tert-butoxy-(9Z,12E)-9,12-tetradecadiene (10). Mass spectrum and ${ }^{13} \mathrm{C}-\mathrm{NMR}$ spectrum of compound 10 are shown in figure 2 and figure 3. 


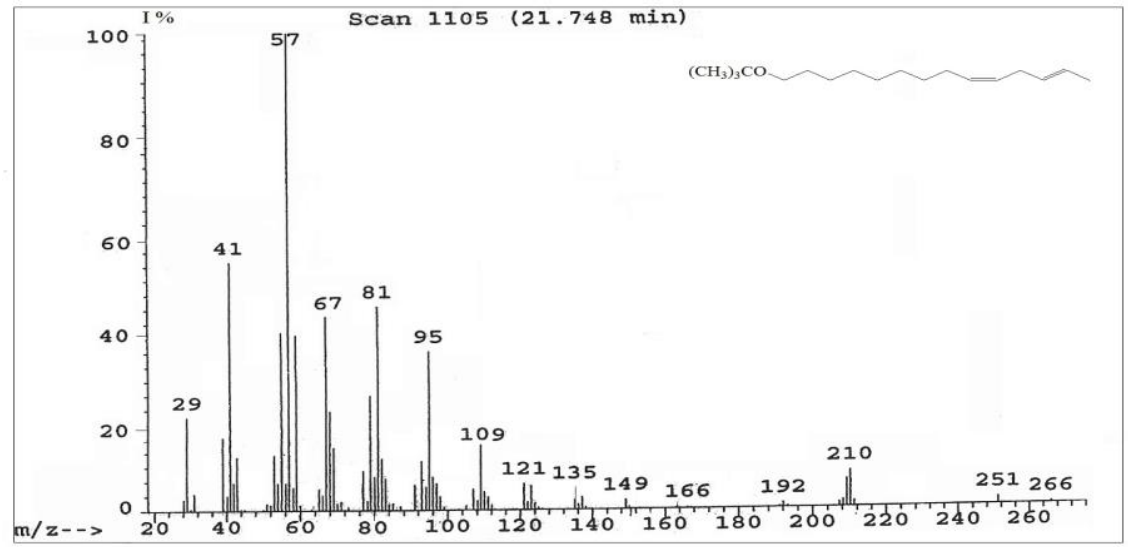

Figure 2. Mass spectrum of 1-tert-butoxy-(9Z,12E)-9,12-tetradecadiene

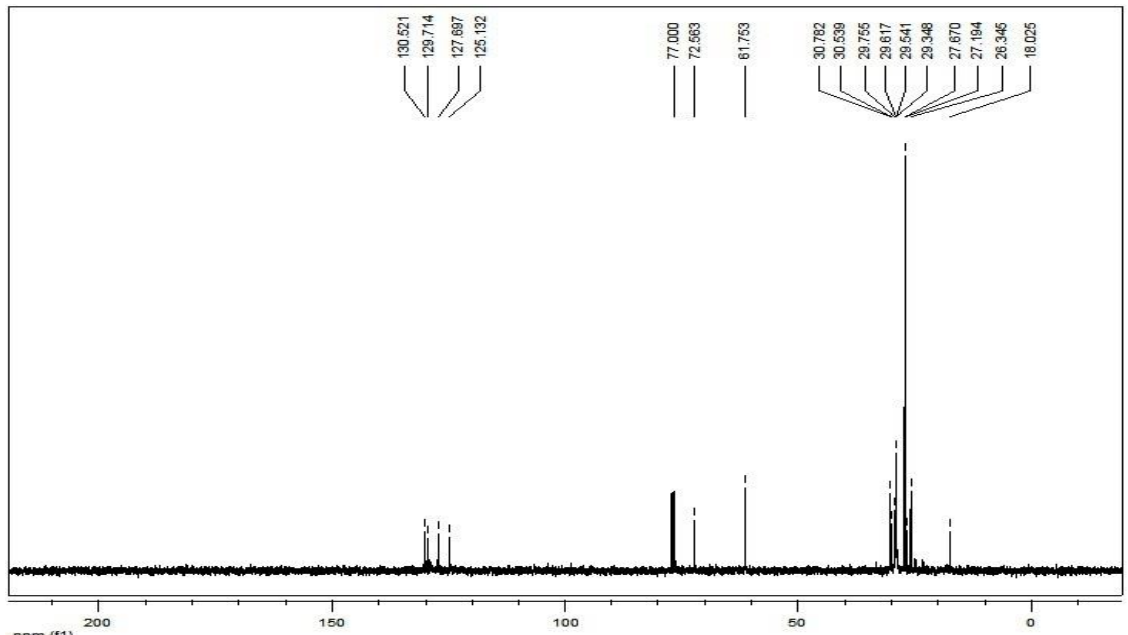

Figure 3. Spectrum ${ }^{13} \mathrm{C}$-RMN of 1-tert-butoxy-(9Z,12E)-9,12-tetradecadiene

The conversion of the tert-butyl ether 10 into acetate 1 was performed with acetic anhydride and boron trifluoride acetic acid complex, obtaining (9Z,12E)-9,12-tetradecadien-1-yl acetate (1) with $82 \%$ isomeric purity.

The mass spectrum of $(9 \mathrm{Z}, 12 \mathrm{E})-9,12$-tetradecadien-1-yl acetate (1) is shown in figure 4 and are characteristic to acetates: $\mathrm{m} / \mathrm{z}$ $=43\left(\mathrm{CH}_{3} \mathrm{CO}^{+}\right)$the base peak, $\mathrm{m} / \mathrm{z}=192$ rezulted from the cleavage of acetic acid from molecular ion, $\mathrm{m} / \mathrm{z}=61$ ion of double transposition $\left(\mathrm{CH}_{3} \mathrm{COOH}_{2}^{+}\right)$.

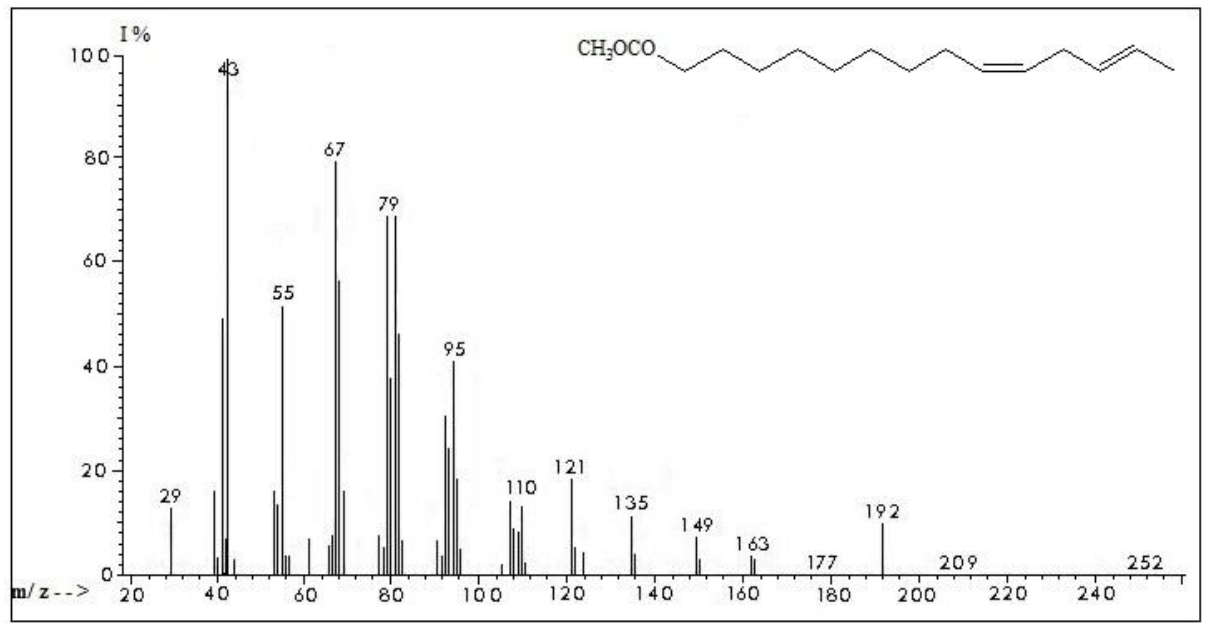

Figure 4. Mass spectrum of (9Z,12E)-9,12-tetradecadien-1-yl acetate 


\section{Conclusions}

It was presented new synthesis of (9Z,12E)-9,12-tetradecadien-1-yl acetate with $82 \%$ isomeric purity. The key step is the transmetallation of the mercury derivative with metal lithium and then alkylated with (E)-1-bromo-2-butene, followed by stereoselective hydrogenation in the presence of $\mathrm{Ni}_{2} \mathrm{P}_{2}$ and acetylation.

\section{References}

1.*** http://www.pherobase.com

2. KASYMZHANOVA, M., ABDUKAKHAROV, V.S., ABDUVAKHABOV, A.A., Chem. Nat. Compd. 28(5), 1992, p. 525.

3. ORTIZ, A., QUESADA, A., SANCHEZ, A., J. Chem. Ecol., 30(5), 2004, p. 991.

4. BOC, N.V., LANGLOIS, Y., J. Am. Chem. Soc. 104, 1982, p. 7666.

5. CHATTOPADHYAY, A., MANDAPUR, V.R., Indian J. Chem., 26B, 1987, p. 868.

6. KASSYMZHANOVA, M., ABDUKAKHAROV, V.S., KAMAEV, F.G., ABDUVAKHABOV, A.A., Chem. Nat. Compd., 25(6), 1990, p. 708.

7. MATVEEVA, E.D., KURTS, A.L., BLOKHIN, A.V., SERGEEV, N.M., BOLKUNOV, I.A., SINITSYNA, E.E., BUNDEL, YU.G., Russ. J. Bioorg. Chem., 14(6), 1988, p. 839.

8. CUVIGNY, C., HERVE DU PENHOAT, JULIA, M., Tetrahedron, 43(5), 1987, p. 859.

9. ISHMURATOV, G.YU., KHARISOV, R.YA., YAKOVLENA, M.P., BOTSMAN, O.V., GALEEVA, R.I., ISHMURATOVA, N.M., TOLSTIKOV, G.A., Russ. Chem. Bull., 47(8), 1998, p. 1595.

10. GÂNSCĂ, L., GOGAN, A., OPREAN, I., MAXIM, S., BUDAE, I., Rev. Roum. Chim., 46(11), 2001, p. 1243.

11. HORNYANSZKY, G., ROHALY, J., NOVAK, L., Synth. Commun., 38, 2008, p. 1533.

12. ODINOV, N., DZHEMILEV, U.M., ISHUMURATOV, G.YU., BOTSMAN, L.P., IBRAGIMOV, A.G., LADENKOVA, I.M., KARGAPOL'TEVA, T.A., ZOLOTAREV, A.P., TOLSTIKOV, G.A., Chem. Nat. Compd., 27(2), 1991, p. 238.

13. BESTMANN, H.J., VOSTROWSKY, O., PLENCHETTE, A., Tetrahedron Lett., 9, 1974, p. 779.

14. MATVEEVA, E.D., ERIN, A.S., LESHCHEVA, I.F., KURTS, A.L., Russ. J. Org. Chem., 36(6), 2000, p. 765.

15. JACOBSON, M., REDFERN, R.E., JONES, W.A., ALDRIDGE, M.H., Science, 170, 1970, p. 542.

16. SU, H.C.F., MANHANY, P.G., BRADY, U.E., J. Econ. Entomol., 66, 1973, p. 845.

17. GOCAN, A. V. M., POP, L. M., CIUPE, H., OPREAN, I., HODOŞAN, P., ROM. Patent No. 93050.

18. HOSKOVEC, M., SAMAN, D., SVATOS, A., Collect. Czech. Chem. Commun., 65, 2000, p. 511.

19. MULLER, E., JOHNSON, J. K., MC EWEN, W. L., J. Amer. Chem. Soc., 48, 1928, p. 469.

20. BROWN, C.A., AHNYA, V. K., Chem. Commun., 1973, p. 553.

$\overline{\text { Manuscript received: 25.03.2019 }}$ 